Journal of Applied Fluid Mechanics, Vol. 14, No. 5, pp. 1469-1482, 2021.

Available online at www.jafmonline.net, ISSN 1735-3572, EISSN 1735-3645.

https://doi.org/10.47176/jafm.14.05.32186

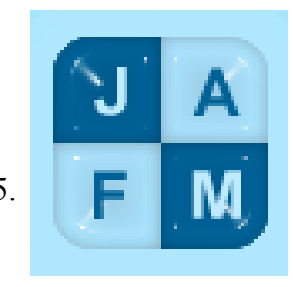

\title{
Patient Specific Modelling of Blood Flow in Coronary Artery
}

\author{
B. Thomas ${ }^{\dagger}$, K. S. Sumam and N. Sajikumar \\ Department of Civil Engineering, Government Engineering College, Thrissur, Kerala, PIN:680009, India \\ †Corresponding Author Email: blessyanna.thomas@gmail.com
}

(Received September 8, 2020; accepted March 2, 2021)

\begin{abstract}
The performance of the heart is considerably affected by the blocks formed because of the deposition of plaque inside the coronary artery. The blocks (stenosis) either in coronary artery or elsewhere force the heart to work harder for pumping the oxygenated blood to the heart muscles and blood vessels. This study analyses the flow through the stenosed coronary arteries via numerical modelling by using ANSYS FLUENT software. Three real cases with different asymmetric stenosis levels (i.e., block level 33\%, 66\% \& 85\%) are analysed by considering blood as a non-Newtonian fluid, and blood flow as pulsatile in nature. As the flow regime falls in transition to turbulent region, the transition Shear Stress Transport (SST) k- $\omega$ turbulence model is used to take care of the changeover stage from laminar to turbulent flow and vice versa. The results show large variation both in Wall Shear Stress (WSS) and pressure drop near the stenosis. Pressure drop becomes more significant at severe degrees of stenosis $(66 \%$ and $85 \%)$ compared to the mild case (33\%). The study throws light on the critical distribution of shear stress and pressure drop along the artery wall, which are considered as indicators of the commencement of heart disease and further growth of stenosis. An indicator, viz., Fractional Flow Reserve (FFR), which relates the percentage of stenosis to the pressure variations, can be used as an index to diagnose the severity of stenosis. All the three cases with different stenotic levels were analysed under hyperaemic conditions and found that even $45 \%$ stenosis case can go near to critical at hyperaemic flow conditions. The effect of severity due to vessel constriction can be estimated by comparing the simulated pressure drop and WSS before and after the stenosis, with the ones for a healthy artery. The present study developed a methodology to calculate FFR value for unknown percentage of stenosis based on the simulated results obtained from $33 \%, 66 \%$ and $85 \%$ stenosis. Thus, criticality of a patient with certain percentage stenosis can also be evaluated. This simulation technique can be recommended as a non-invasive diagnostic tool for the early detection of atherosclerosis.
\end{abstract}

Keywords: Coronary artery; Stenosis; Wall shear stress; Flow rate - Pressure relation; Fractional flow reserve.

\section{NOMENCLATURE}

$\begin{array}{ll}\mathrm{A} & \text { cross-section area, } \mathrm{m}^{2} \\ \mathrm{D} & \text { cross diffusion } \\ \mathrm{D} & \text { artery diameter } \\ \mathrm{G} & \text { generation term } \\ \mathrm{k} & \text { phase average turbulent kinetic energy } \\ n & \text { power index } \\ \mathrm{n} & \text { unit vector } \\ p & \text { pressure, } \mathrm{Pa} \\ \overline{\mathrm{P}} & \text { mean pressure, } \mathrm{Pa} \\ \mathrm{Q} & \text { flow rate, } \mathrm{m}^{3} / \mathrm{s} \\ \overline{\mathrm{Q}} & \text { mean flow rate, } \mathrm{m}^{3} / \mathrm{s} \\ \mathrm{R}_{\mathrm{m}} & \text { artery radius } \\ \mathrm{T} & \text { time period } \\ \mathrm{t} & \text { time, } \mathrm{s} \\ \mathrm{u} & \text { velocity vector, } \mathrm{m} / \mathrm{s}\end{array}$

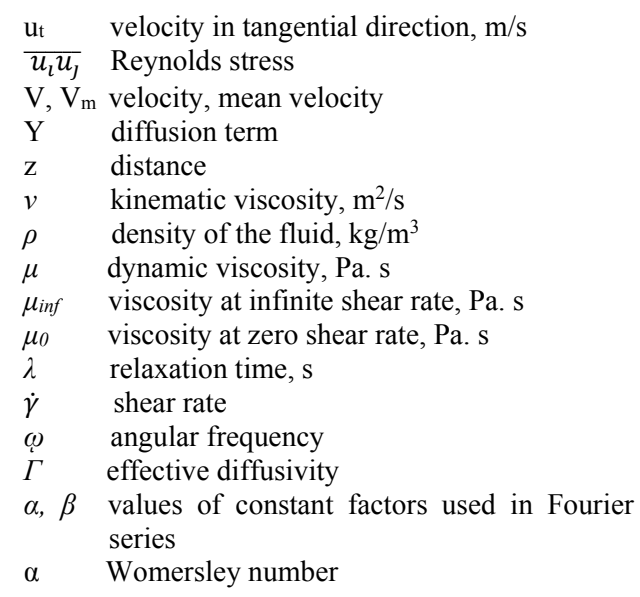




\section{INTRODUCTION}

One of the most common heart diseases leading to millions of death across the globe is Coronary Artery Disease (CAD); and its major symptoms include angina (chest pain), shortness of breath, and heart attack. CAD is very critical under hyperaemic condition, a condition of blood vessel in which higher volume of blood passes through it while doing activities like sprinting and heavy exercise. The present study focuses on hyperaemic cases during which the heart has to pump extra blood. Pumping of extra blood to other part of the body demands higher volume of blood to the heart muscles and leads to expansion of the coronary artery. Stenosis (occlusion due to building up of plaques) causes hindrance to blood flow towards heart muscles and worsen CAD like atherosclerosis in hyperaemic condition. Stenosis is influenced by the geometry of the vessel (bends, branching) and biomechanical factors like Wall Shear Stress (WSS), viscosity of blood, blood Pressure. WSS is defined as the tangential stress on the endothelial surface of the arterial wall derived from the friction of the flowing blood. Hyperaemic flow condition in stenosed artery can lead to the breakage of blood vessels and insufficient flow to heart muscles which can cause heart failures. Hence, the study of stenosed arteries under hyperaemic condition is of prime importance. Since the in-vivo investigation of hemodynamic characteristics at real environment is practically impossible, Computational Fluid Dynamics (CFD) analysis of stenosed artery under hyperaemic condition is found to be an effective tool for such studies (Jabir and Lal 2016; Mahalingam et al. 2016) and is used in the present study.

The blood flow can be assumed as Newtonian in large sized arteries like aorta (Fung 1997) while it should be considered as non-Newtonian in small vessels like capillaries (Pedley 1980; Fournier 2007). Johnston et al. (2004 and 2006) and Thomas and Sumam (2016) observed that the Carreau model was found to give reasonable results for the analysis of blood flow studies among the available nonNewtonian models.

The blood flow inside an artery vessel is generally laminar in nature $(\operatorname{Re}<1000)$. Stein and Sabbah (1976) found highly disturbed flow near the aortic valve during a peak ejection with Re ranges from 5,700 to 8,900. Deshpande and Giddens (1980) studied the steady and turbulent flow (with the Reynolds numbers in the range of 5000 to 15000) through a $75 \%$ stenosed tube by using Laser Doppler Anemometer (LDA). The results showed high levels of turbulence in recirculation region. Ahmed and Giddens (1983) measured the steady velocity fields with Reynolds number in the range of 500 to 2000 in a stenosed tube with rigid wall by using LDA. The periodic oscillations accompanied by random fluctuation and turbulent flow were observed in a steady flow through a severely stenosed tube at high values of Re. Winter and Nerem (1984) observed temporary turbulent flow even at low average Reynolds number $(\operatorname{Re}<=400)$ during the deceleration of an oscillatory flow and then the flow returned to laminar. Ahmed and Giddens (1984) conducted pulsatile flow experiments and found that the post stenotic flow changed to turbulent only at certain phases of the cardiac cycle and the flow got back to laminar quickly. Ojha et al. (1989) observed isolated regions of vertical and helical structures at the deceleration phase of the flow cycle under mild stenosis levels of less than $50 \%$ and found that the observed effect was more in case of asymmetric stenosis. This study also reported that the transition to turbulent flow was triggered at high stenosis levels.

The numerical studies on hemodynamic flow under steady or unsteady condition with "ReynoldsAveraged Navier-Stokes" (RANS) CFD codes sporadically considered the transition from laminar to turbulent. Quite a few numerical studies used two equations, low-Re turbulence model for the flow studies of symmetrical stenosis in a straight tube (Ghalichi et al. 1998; Bluestein et al. 1999; Varghese et al. 2003; Ryval et al. 2004; Banks and Bressloff 2007). Low-Re RANS turbulence model was used by Ghalichi et al. (1998) for the simulation of $50 \%, 75 \%$ and $86 \%$ stenosed flow in arteries. That model showed that the Wilcox low-Re turbulence model predicted better results than the standard k-epsilon model. Varghese et al. (2003) employed four different turbulence models for analysing pulsatile turbulent flow in stenotic vessels and found that the results from $\mathrm{k}-\omega$ turbulence model were better and were in good agreement with experimental measurements. It was found that the WSS reached a maximum value at the throat of the stenosis and diminished towards the distal ends. The prediction of WSS and the turbulence transition are better captured in transition SST k- $\omega$ model than in RANS based model (Ryval et al. 2004; Tan et al. 2008; Mahalingam et al. 2016). The physiological parameters and processes like pressure loss, WSS, plaque collection and wall remodelling influence the disturbances in arterial blood flow (Tan et al. 2008; Davies et al. 1986). Samady et al. (2011) studied the importance of low WSS by collecting patient data and evaluated the values of coronary WSS with respect to plaque progression. The study concluded that the low-WSS segments developed greater plaque and necrotic core progression than intermediate-WSS coronary segments. Jabir and Lal (2016) investigated the steady and pulsatile flows past an elliptic-vertically shifted stenosis using CFD with LES (Large Eddy Simulation) in carotid artery. They found that the velocity profile at a section immediately after the stenosis was skewed toward the opposite side of the blocked part in a flow through an asymmetric stenosis. The investigators observed that the uneven distribution of WSS over the wall along the geometric unevenness of stenosis was due to turbulent breakdown of jet. Mahalingam et al. (2016) quantitatively analyzed turbulent transition during pulsatile flow through coronary arteries for varying degree of stenosis (i.e., $0 \%, 30 \%$, $50 \%$ and $70 \%$ ) by considering arterial wall as rigid using transition SST k- $\omega$ model. The investigators found that the intensity of turbulence increases significantly for $70 \%$ stenosis compared to $50 \%$ or lower. It was found that the onset of transition to 
turbulent flow seemed to occur from $50 \%$ stenosis. Jahangiri et al. (2017) studied non-Newtonian pulsatile flow of blood through an elastic blood artery with single and consecutive stenosis. Kumar et al. (2018) investigated the relationship between low WSS and severe endothelial dysfunction using patient specific data. The analysis concluded that segments with low WSS demonstrated greater vasoconstriction than segments with intermediate or high WSS.

Mahalingam et al. (2016) mentioned about the importance of FFR for the early detection of cardiovasucular disease and stroke, however no limiting value is specified. Fractional Flow Reserve (FFR) is defined as the ratio of pressure upstream of a stenosis to the pressure downstream of the stenosis. The FFR index is an absolute number and can be used to represent the severity of stenosis in coronary artery as this index is customarily used as a mathematical check for the clinical estimation of atherosclerosis. The FFR of 0.80 means that $20 \%$ drop in blood pressure is caused by the stenosis. Normally, a pressure transducer catheter is needed to measure the flow across the stenosis to calculate the FFR. A FFR threshold value of 0.8 is clinically used to identify the patients (with coronary lesions) who get benefited by coronary revascularization therapy (De Bruyne et al. 2012; Muller et al. 2011; Nørgaard et al. 2014). The patient can be treated with medications for lesion-specific ischemia for FFR $>0.8$. Nonetheless, when the FFR value is in the range of 0.8 to 0.75 or lower, detailed clinical evaluations must be conducted to affirm the diagnosis (Pijls and Sels 2012). This indirectly indicates the importance of FFR in diagnosing and determining CAD more accurately. Now, the FFR values can be obtained clinically by using invasive technique. Invasive techniques are difficult to perform and inconvenient to the patients. If a noninvasive method is available which can ascertain the FFR value, the tedious and difficult procedures can be avoided. Though there are several studies which model the relation between stenosis and FFR, most of them uses the hypothetical stenosis pattern rather than using the actual shape of the stenosis. Hence the present study aims to relate the stenosis with FFR values by using actual shape of patient specific stenosis (obtained from CT scan) so that invasive technique can be avoided to some extent.

In this study, the blood flow rate vs pressure relationship across three different patient cases, having different degree of asymmetric stenosis (33\%, 66\% \& 85\% stenosis) was investigated. A realistic physiological pulsatile flow profile is applied to mimic the blood flow inside the coronary arteries. It is also noted that the studies related to patient specific cases (with asymmetric stenosis) has not been modelled with the transition SST k- $\omega$ model with the hyperaemic blood flow conditions so far. Hence, the present work contributes towards an improvement in CFD modelling for the better prediction of WSS and FFR in a patient specific stenosed artery under hyperaemic condition. The study tries to link the stenosis with FFR and flow rates and hence can become aid in understanding the early signs of cardiovascular diseases during clinical diagnosis using non-invasive methods.

\section{Materials And Methods}

\subsection{Geometry construction and computational mesh generation}

Computer tomography (CT) images of three patient cases with significant levels of stenosis are used for the study. The lumen and wall surface of the coronary artery are obtained from CT image. A software VMTK (Vascular Modelling Tool Kit) (Antiga et al. 2008) is used for tracing the lumen portion of the blood vessel from CT images. The commercially available ICEM CFD 3D modeller is used to generate and prepare the required surface. Another 3D modelling software SOLIDWORKS is used for smoothening of the surface. The 3D computational models of the three asymmetric geometries which are generated from the CT scan are shown in Fig. 1. In order to attain a fully developed flow, the end sections of the specimen were extended 5 times the diameter of vessel at the inlet and outlet. Computational mesh for coronary artery with $66 \%$ stenosis is shown in Fig. 2.

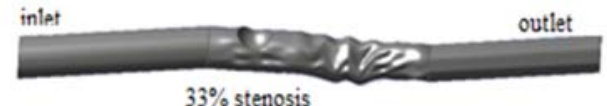

(a)

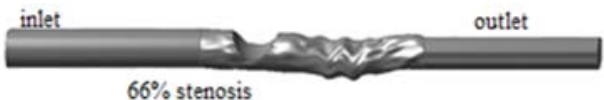

(b)

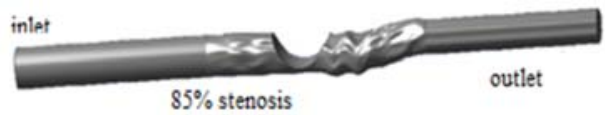

(c)

Fig. 1. 3-D Geometric model for (a) Patient 1$33 \%$ stenosis; (b) Patient 2- 66\% stenosis; (c) Patient 3- 85\% stenosis.

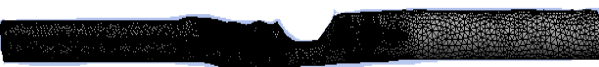

(a)

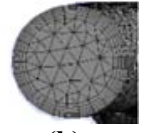

(b)

Fig. 2. Computational mesh (a) 3-D computational mesh for coronary artery with $66 \%$ stenosis; (b) Enlarged view of the mesh at inlet.

Unstructured tetrahedral elements are used for the grid generation. To capture the boundary layer effects, prism elements are attached to the walls (Fig. $2 \mathrm{a} \& \mathrm{~b})$. A wall, having four layers of prism elements with a height ratio of 1.2 , is utilised to capture the flow near the wall (Fig. 2b). The value of $y+$ in the first grid for the $66 \%$ stenosis case is 0.5 away from the wall as per the requirement of the turbulent 
transition model (ANSYS 18.2 2017). Four cardiac cycles are considered for each transient simulation to ensure periodicity. To avoid the initial fluctuation, which occurs at the starting of the simulation, the results were analysed from the third cycle onwards. The same procedure was adopted for the other two cases of $33 \%$ and $85 \%$ stenosis.

\subsection{Governing Equations}

Navier Stokes' Equations as given in equation 1 and 2 govern the blood flow in coronary arteries (Anderson 1995; Hinze 1975; Ansys 2017). ANSYS (2017), a commercial CFD software, was used for carrying out computational investigations.

$$
\begin{aligned}
& \frac{\partial U_{i}}{\partial x_{i}}=0 \\
& \frac{\partial U_{i}}{\partial t}+U_{j} \frac{\partial U_{i}}{\partial x_{j}}=\frac{\partial}{\partial x_{j}}\left[v \frac{\partial U_{i}}{\partial x_{j}}-\overline{u_{i} u_{j}}\right]-\frac{1}{\rho} \frac{\partial p}{\partial x_{j}}
\end{aligned}
$$

where, $U_{i}$ represents mean velocity vector, $p$ represents static pressure, $\rho$ represents fluid density, $\overline{u_{\imath} \bar{u}_{\jmath}}$ represents Reynolds stress and $v$ represents kinematic viscosity $(\mu / \rho)$. Considering the non-Newtonian behaviour of blood, Carreau model is used in this study. The dynamic viscosity of the blood, $\mu$ is calculated by using the equation (3), given as

$\mu=\mu_{i n f}+\left(\mu_{0}-\mu_{i n f}\right)\left(1+(\lambda \gamma)^{2}\right)^{\frac{n-1}{2}}$

where $\mu_{0}$ represents viscosity at zero shear rate, $\mu_{\text {inf }}$ represents viscosity at infinite shear rate, $\lambda$ represents relaxation time, $n$ represents power index and $\dot{\gamma}$ represents the shear rate. Values of the constants and the values of human blood properties are taken from the literature, Johnston et al. (2004), as $\mu_{0}=0.056 \mathrm{~Pa}$ $\mathrm{s}, \mu_{\text {inf }}=0.00345 \mathrm{~Pa} \mathrm{~s}, \lambda=3.313 \mathrm{~s}, n=0.3568$. The assumptions made for the analysis are

i. Flowing fluid (blood) is incompressible and homogeneous.

ii. Blood is assumed to be non-Newtonian fluid.

iii. Artery wall is deemed as rigid.

iv. The cardiac muscle movements are neglected.

For incompressible fluids and non-slip conditions applied at the arterial wall, the spatial wall shear stress is calculated as

$\mathrm{WSS}=-\mu \frac{\partial \mathrm{u}_{\mathrm{t}}}{\partial \mathrm{n}}$

where $\mu$ is the dynamic viscosity, $\mathrm{ut}_{\mathrm{t}}$ the wall velocity in tangential direction and ' $n$ ' is the unit vector perpendicular to the wall.

\section{Boundary conditions}

The blood flow rate at the arterial inlet is calculated by the following equation (5) and it is represented as a pulsatile velocity (Wiwatanapataphee et al. 2012).
$\mathrm{U}(\mathrm{t})=\frac{\mathrm{Q}(\mathrm{t})}{\mathrm{A}}$

where A represents cross-sectional area of the arterial inlet, $\mathrm{Q}(\mathrm{t})$ represents pulsatile flow rate and is represented as a waveform, obtained by the Fourier series. The pressure at the arterial outlet was also represented as pulsatile boundary condition, expressed by Fourier series (Wiwatanapataphee et al. 2012; Attinger et al. 1966). The expressions related to the pulsatile flow rate and pulsatile pressure are given in following equations $(6 \& 7)$ and depicted graphically in Fig. 3. At the inlet, the flow Reynolds number based on the inlet diameter of the artery reaches a maximum value of 450 , during peak systole.

$\mathrm{Q}(\mathrm{t})=\overline{\mathrm{Q}}+\sum_{\mathrm{j}=1}^{4} \alpha_{\mathrm{j}}^{\mathrm{Q}} \cos (\mathrm{j} \omega \mathrm{t})+\beta_{\mathrm{j}}^{\mathrm{Q}} \sin (\mathrm{j} \omega \mathrm{t})$
$\mathrm{p}(\mathrm{t})=\overline{\mathrm{p}}+\sum_{\mathrm{j}=1}^{4} \alpha_{\mathrm{j}}^{\mathrm{p}} \cos (\mathrm{j} \omega \mathrm{t})+\beta_{\mathrm{j}}^{\mathrm{p}} \sin (\mathrm{j} \omega \mathrm{t})$

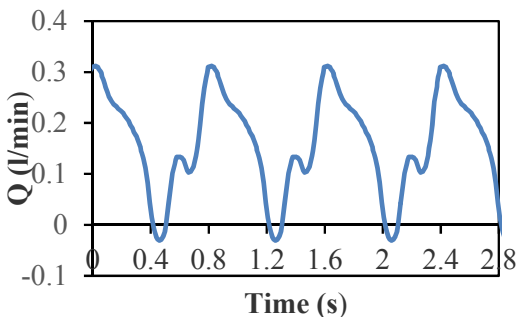

(a)

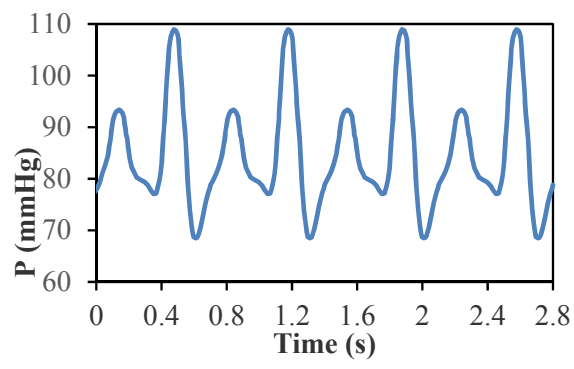

(b)

Fig. 3. Boundary conditions. (a) Volumetric flow rate of blood in the arterial inlet; (b) The pulsatile pressure of blood in the arterial outlet.

where $\mathrm{Q}(\mathrm{t})$ represents the pulsatile flow rate, mean volumetric flow rate $\overline{\mathrm{Q}}=0.1589 \mathrm{l} / \mathrm{min}, \omega=2 \pi / \mathrm{T}$ is the angular frequency with a time period $\mathrm{T}=0.8 \mathrm{~s}, \overline{\mathrm{p}}$ is the mean pressure and is equal to $\overline{\mathrm{p}}=84.9722 \mathrm{mmHg}$. A varying mean flow rate $\bar{Q}(0.158,0.237,0.316,0.395$ and $0.553 \mathrm{l} / \mathrm{min}$ ) from the normal to hyperaemic was applied at the inlet (Wiwatanapataphee et al. 2012). The constants relate to the normal flow of the Fourier series equations (6) and (7) are summarized in Table 1. For hyperaemic flow conditions at the inlet, the flow profiles of Fig. $3 \mathrm{a}$ is modified with a flow rate corresponding to hyperaemic condition. Pressure 
profiles at the outlet are then computed corresponding to the generated flow rate profile at the inlet under hyperaemic condition.

Table 1 Values of constant factors used in Fourier series equations (Eq. 6 \& 7) for representing the pulsatile flow rate and the pressure variation under normal condition (Wiwatanapataphee et al. 2012)

\begin{tabular}{|c|c|c|c|c|}
\hline $\mathrm{J}$ & $\alpha_{\mathrm{j}}^{\mathrm{Q}}$ & $\beta_{\mathrm{j}}^{\mathrm{Q}}$ & $\alpha_{\mathrm{j}}^{\mathrm{p}}$ & $\beta_{\mathrm{j}}^{\mathrm{P}}$ \\
\hline 1 & 0.1007 & 0.0764 & -3.3107 & -2.2932 \\
\hline 2 & -0.0034 & -0.0092 & -9.8639 & 8.0487 \\
\hline 3 & 0.0294 & 0.0337 & 3.0278 & 3.8009 \\
\hline 4 & 0.0195 & -0.0129 & 2.2476 & -3.2564 \\
\hline
\end{tabular}

\subsection{Transition Shear Stress Transport (SST) k- $\omega$ turbulence model}

Unsteady flow simulations are carried out by using transition SST k- $\omega$ model (Tan et al. 2008; Mahalingam et al. 2016), which is based on the coupling of Menter's k- $\omega$ transport equations with other two transport equations. Out of this, one is for the intermittency and the other was for the transition onset criteria. Both are defined with respect to the Reynolds number in the momentum thickness. Menter's SST model is utilized to blend the robust and accurate formulation of the $k-\omega$ model effectively in the near-wall regions along with a free stream independence of the $\mathrm{k}-\omega$ model in the far field (Tan et al. 2008).

The transport equations for $\mathrm{k}$ and $\omega$ are given in equations $8 \& 9$.

$$
\begin{aligned}
& \frac{\partial(\rho \mathrm{k})}{\partial \mathrm{t}}+\frac{\partial\left(\rho \mathrm{ku}_{\mathrm{i}}\right)}{\partial \mathrm{x}_{\mathrm{i}}}=\frac{\partial}{\partial \mathrm{x}_{\mathrm{i}}}\left[\Gamma_{\mathrm{k}} \frac{\partial \mathrm{k}}{\partial \mathrm{x}_{\mathrm{j}}}\right]+\mathrm{G}_{\mathrm{k}}+\mathrm{Y}_{\mathrm{k}} \\
& \frac{\partial(\rho \omega)}{\partial \mathrm{t}}+\frac{\partial\left(\rho \omega \mathrm{u}_{\mathrm{j}}\right)}{\partial \mathrm{x}_{\mathrm{i}}}=\frac{\partial}{\partial \mathrm{x}_{\mathrm{i}}}\left[\Gamma_{\omega} \frac{\partial \omega}{\partial \mathrm{x}_{\mathrm{j}}}\right]+\mathrm{G}_{\omega}+\mathrm{Y}_{\omega}+\mathrm{D}_{\omega}(9)
\end{aligned}
$$

where $\Gamma$ is the effective diffusivity, $G$ represents generation term, $\mathrm{Y}$ represents diffusion term and $\mathrm{D}$ is the cross diffusion.

\subsection{Validation of Shear Stress Transport (SST) k- $\omega$ turbulence model}

To validate this model, a $75 \%$ axisymmetric constriction carrying pulsatile flow is simulated (Ahmed and Giddens 1984). The idealized stenosed geometry is used for the validation, as shown in Fig.4a. Based on the Womersley's solution, a fully developed pulsatile velocity profile was specified (Fig. 4b) at the inlet of idealized geometry. Zero pressure was applied at the outlet. In order to get rid of the error in the assumption at the point of interest (immediately after the stenosis), extra length is modelled (14D) and outlet condition is provided at the end of the additional length. The maximum and minimum value of $\operatorname{Re}$ were 1000 and 200 respectively. Womersley number, $\alpha$ chosen for this experimental study is 7.5. Standard SST k- $\omega$ parameters values are used in the study. The axial velocity profiles corresponding to peak flow rate are plotted and compared with the experimental values of Ahmed and Giddens (1984) at $Z=1 D$ and $Z=0$ as shown in Figs. 5 and 6 . The result shows good agreement with the experimental values, validating the selection of SST k- $\omega$ turbulence model for the present study. Figure 5 shows that the present study gives better results than the published results dealing with the same problem (Varghese et al. 2007). Figure 6 shows the comparison of computed results with experimental results at $Z=0$. The error in computation is slightly higher than that at $Z=1 D$. However, there is no computational results available for comparison from literature.
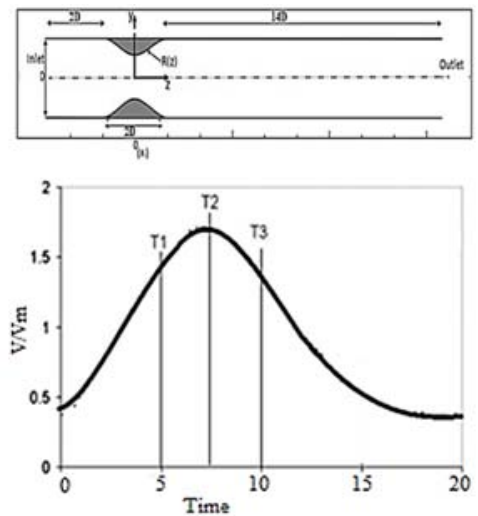

Fig. 4. (a) Idealized stenosed geometry; (b) Inlet pulse.

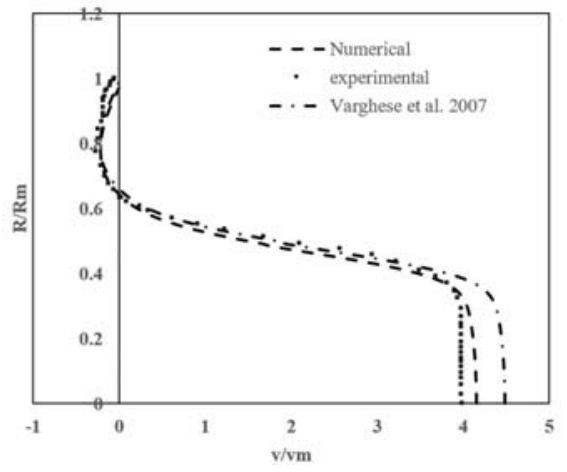

Fig. 5. Axial velocity profiles at $Z=1 D$ corresponding to peak flow rate.

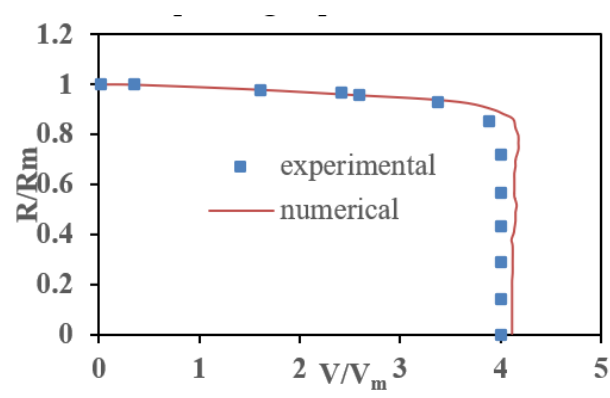

Fig. 6. Axial velocity profiles at throat $(\mathrm{z}=0)$ corresponding to peak flow rate. 


\subsection{Grid independence study of patient specific model}

A grid independence study was carried out for patient specific model for $66 \%$ stenosis. The study considered three tetrahedral meshes (M1, M2 and M3) having mesh elements 101284, 467009 and 687564 as shown in Table 2. To establish the grid independence, the results of WSS at the maximum flow conditions for various meshing levels M1, M2 and M3 were compared. The results showed a minor error in WSS between M2 and M3 (1.1\%). Hence the mesh M2 is taken for further investigation. In short, the final model with $66 \%$ stenosis have 467009 elements. Grid Convergence Index is calculated in this case and obtained value is $0.048 \%$ (Celik et al. 2008). Similarly, the final models for $33 \% \& 85 \%$ cases have 423208 and 497000 elements respectively.

Table 2 Grid independence study for the case, with $66 \%$ stenosis.

\begin{tabular}{|l|c|c|c|c|}
\hline No & Name & mesh & $\begin{array}{c}\text { WSS } \\
(\mathrm{Pa})\end{array}$ & $\begin{array}{c}\text { Change in } \\
\text { WSS (\%) }\end{array}$ \\
\hline 1 & M1 & 101284 & 11.325 & - \\
\hline 2 & M2 & 467009 & 12.87 & 13.6 \\
\hline 3 & M3 & 687564 & 13.013 & 1.1 \\
\hline
\end{tabular}

\section{RESULTS AND DISCUSSIONS}

\subsection{Wall Shear Stress}

In an atherosclerosis patient, the arterial wall becomes more rigid than the normal and blood carrying capacity of the artery is also less (Garcia et al. 2006; Jabir and Lal 2016). In this case, the CFD technique is used to investigate the distribution of WSS in different patient specific cases of coronary artery having varying degrees of stenosis under normal to hyperaemic flow condition. High blood flow rates along with high WSS occurring in a severely stenosed coronary artery vessel can create platelet adhesion regions contributing to plaque rupture (Fry 1969). Hence, an attempt was made to evaluate WSS at three levels of stenosis for different phases of cardiac cycle.

Table 3 WSS variation in an artery (without stenosis)

\begin{tabular}{|c|c|c|}
\hline \multirow{2}{*}{$\begin{array}{c}\text { Diameter } \\
(\mathrm{D})(\mathrm{mm})\end{array}$} & \multicolumn{2}{|c|}{ WSS $_{\max }$ at peak systole } \\
\cline { 2 - 3 } & Normal & Hyperaemic \\
\hline 3 & 8.33 & 37.29 \\
\hline 3.21 & 6.67 & 28.59 \\
\hline 4 & 3.68 & 14.45 \\
\hline
\end{tabular}

To study the impact of stenosis size on WSS, zero stenosis cases are also simulated for the diameters 3 $\mathrm{mm}, 3.21 \mathrm{~mm}$ and $4 \mathrm{~mm}$, corresponding to the three patient specific coronary artery sizes. A pulsatile discharge (Fig. 3a) and pressure (Fig. 3b) was applied as the boundary condition at the in the inlet and outlet. The WSS variation for the normal (mean flow rate $=0.158 \mathrm{l} / \mathrm{min}$ ) and the hyperaemic flow (mean flow rate $=0.553 \mathrm{l} / \mathrm{min}$ ) are simulated between the inlet and the outlet and are shown in Table 3. The simulation results lie within range of normal healthy person (2 to $16 \mathrm{~Pa}$, Cheng et al. 2007).

Now, the simulation is carried out for the stenosis cases with the stenosis percentages $33 \%, 66 \%$ and $85 \%$ respectively. The instantaneous variation of WSS $(x=0, x=1 D$ and $x=5 D$, where $x=0$ is the start of CT scan image in all cases, and D is the diameter) for $33 \%, 66 \%$, and $85 \%$ stenosis for normal and hyperaemic flows at the $3^{\text {rd }}$ cardiac cycle is shown respectively in Fig. 7a1, a2, a3 and 7b1, b2, b3. The WSS levels for healthy arteries were reported to vary between 2 to $16 \mathrm{~Pa}$ (Cheng et al. 2007) under normal flow condition. This is the range within which WSS should fall; higher or lower value beyond this range is bad for the patient. However, the WSS value of the aforementioned cases with different stenosis levels vary between a wide band (4.13 to $701.42 \mathrm{~Pa}$, from normal to hyperaemic flow according to the location and the level of stenosis) as indicated in Table 4. At $\mathrm{x}=1 \mathrm{D}$, normal flow condition of $33 \%$ case, WSS values vary between 5.21 to $0.063 \mathrm{~Pa}$, whereas these values vary between 154.11 to $0.06 \mathrm{~Pa}$ for $66 \%$ case and 140.6 to $0.107 \mathrm{~Pa}$ for $85 \%$ case respectively. Figures $7 \mathrm{a} 1$ and $\mathrm{a} 3(\mathrm{x}=0 \& \mathrm{x}=5 \mathrm{D})$ shows that the higher WSS values for all the cases at normal flow condition are close to the maximum limit of the allowable range (Cheng et al. 2007), whereas one can see a substantial increase in WSS at hyperaemic condition for all cases and locations. However, the lower values of WSS deviate from the minimum limit of the allowable range in proportion to the increase in stenosis percentage. The WSS attains its peak value during systole, and reaches its lowest value in the decelerating phase of the systole.

Higher values of WSS lead to maximum damage of endothelial cell in arteries. At some phase of cardiac cycle, the WSS goes below the physiological levels of $(2 \mathrm{~Pa})$, leading to accumulation of plaques aiding the progression of stenosis (Fig 7a1, a2, a3 and 7b1, b2, b3). Thus, high and low values of the WSS for an artery are critical for the initiation and progression of the atherosclerosis. By comparing the graph of both flow conditions, it was found that the WSS values near the location of stenosis increased with the flow rate. The maximum WSS values at $\mathrm{x}=1 \mathrm{D}$, under the hyperaemic condition of $33 \%, 66 \%$ and $85 \%$ stenosis cases are $368.02 \mathrm{~Pa}, 701.42 \mathrm{~Pa}$ and $625.56 \mathrm{~Pa}$ respectively, which are much higher than the values in normal condition. It is observed from Fig.7a and $7 \mathrm{~b}$ that the shape of WSS curve closely reproduces the shape of the flow curve (Fig. 3a). The study reveals that, near the endothelial surface, the WSS is a function of velocity gradient of blood flow. Thus, a sudden change in the velocity gradient because of the constriction can contribute to substantial change in WSS values (Samady et al. 2011).

The percentage changes in the maximum WSS with respect to the percentage of stenosis are also quantified and it is found that the percentage increase in WSS ranges from $54 \%$ to $136 \%$ in respective cases at hyperaemic flow condition (Table 4). 

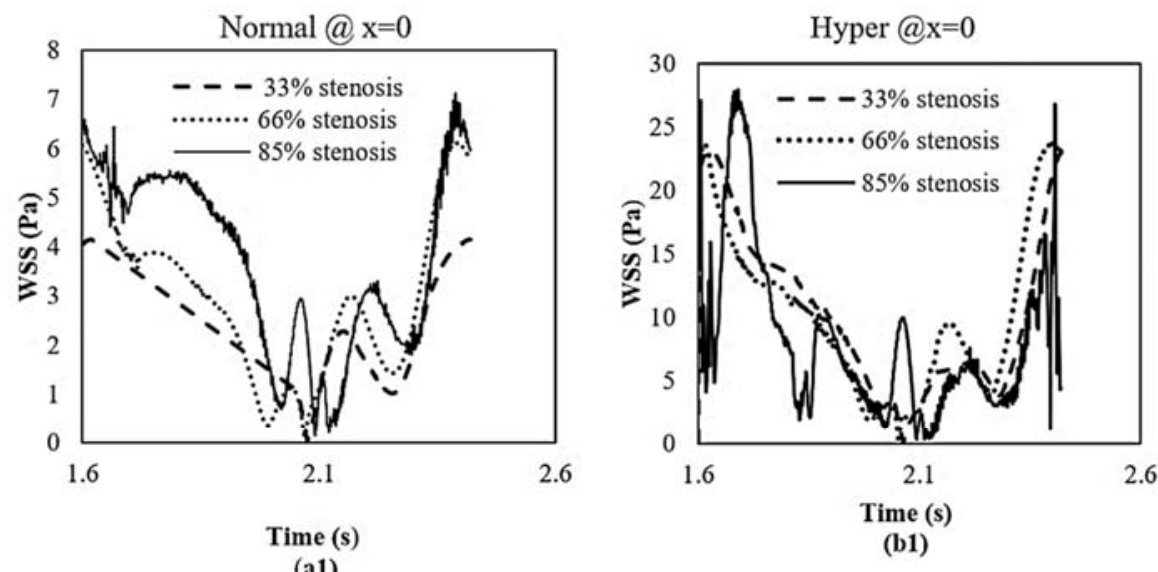

(a1)
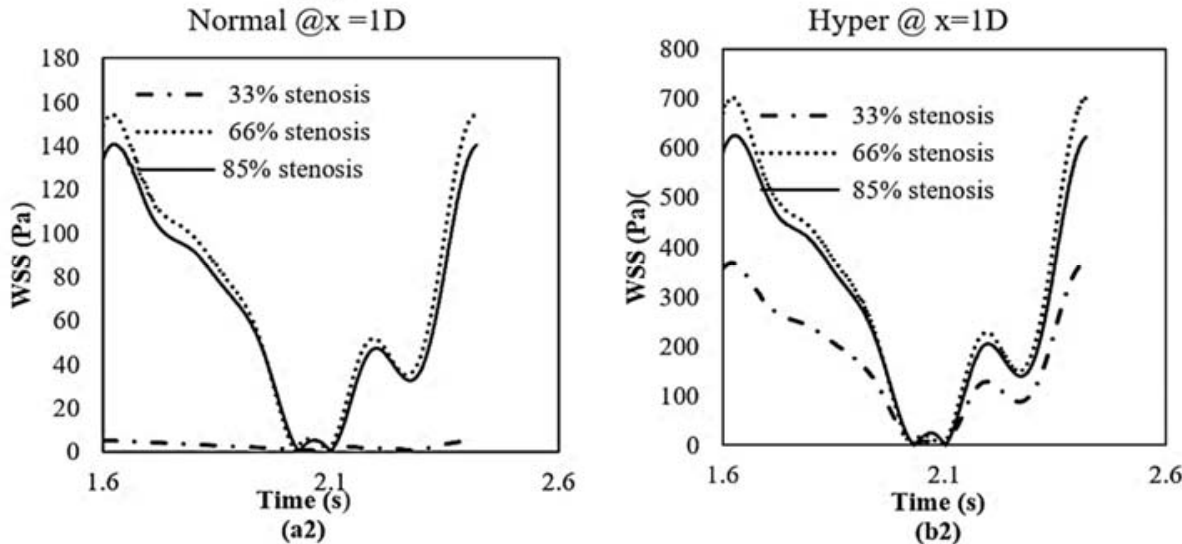

Normal@x=5D

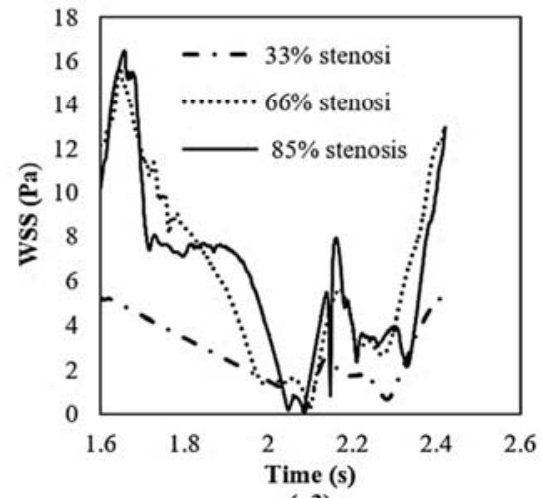

(a3)

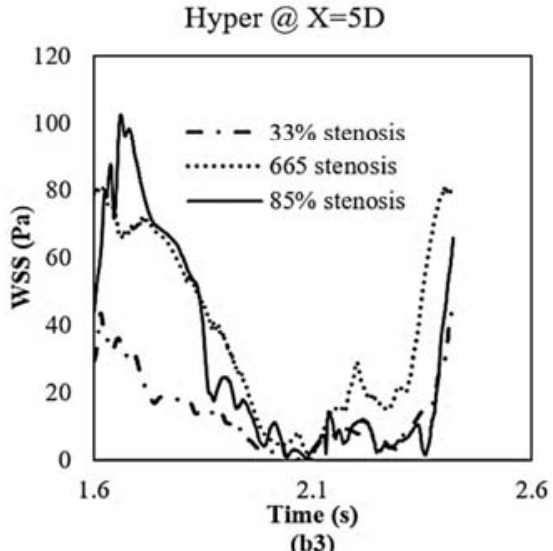

Fig. 7 a1, a2, a3 WSS at $x=0, x=1 D, x=5 D$ for $33 \%, 66 \%$ and $85 \%$ stenosis in normal condition and b1, b2, b3 in hyperaemic condition.

However, at the critical position $(x=1 \mathrm{D}$, close to the stenosis), the WSS increases by $350 \%$ when the flow changes from normal to hyperaemic flow condition for $66 \%$ and $85 \%$ case. It is concluded that the percentage increase in WSS is very high with the increase in degree of stenosis when flow changes from normal to hyperaemic condition and it also depends upon the location of stenosis.

\subsubsection{WSS variation along the artery wall}

The behaviour of WSS is an important factor in the progression of wall deformations in vessels and subsequent wall rupture. The WSS acts as a function of the velocity gradient of blood near the endothelial area and both are concomitant (Samady et al. 2011). Hence, even a small variation of velocity gradient can lead to large effects on the WSS. The figures 8 , 9 and 10 represents various plots of WSS along the vessel wall at different phases of the flow pulse for the different stenosis cases under normal and hyperaemic flow conditions.

The plot shown in Fig. 8a represents the WSS distribution of $33 \%$ stenosis case, along the arterial 
Table 4 Maximum and minimum value of WSS under normal and hyperaemic flow.

\begin{tabular}{|c|c|c|c|c|}
\hline \multirow{3}{*}{$\begin{array}{c}\text { Diameter } \\
\text { (D) }(\mathrm{mm}) / \% \text { stenosis }\end{array}$} & \multicolumn{4}{|c|}{ Location $\mathrm{X}=0$} \\
\hline & \multicolumn{2}{|c|}{$\mathrm{WSS}_{\max }(\mathrm{Pa})$} & \multicolumn{2}{|l|}{$\mathrm{WSS}_{\min }(\mathrm{Pa})$} \\
\hline & Normal & Hyperaemic & Normal & Hyperaemic \\
\hline $3(33 \%)$ & 4.13 & 18.12 & 0.026 & 0.42 \\
\hline $3.21(66 \%)$ & 6.10 & 23.85 & 0.10 & 0.34 \\
\hline $4(85 \%)$ & 7.09 & 27.98 & 0.13 & 0.28 \\
\hline \multirow{3}{*}{$\begin{array}{c}\text { Diameter } \\
\text { (D) }(\mathrm{mm}) / \% \text { stenosis }\end{array}$} & \multicolumn{4}{|c|}{ Location $\mathrm{X}=1 \mathrm{D}$} \\
\hline & \multicolumn{2}{|c|}{$\mathrm{WSS}_{\max }(\mathrm{Pa})$} & \multicolumn{2}{|c|}{$\mathrm{WSS}_{\min }(\mathrm{Pa})$} \\
\hline & Normal & Hyperaemic & Normal & Hyperaemic \\
\hline $3(33 \%)$ & 5.21 & 368.02 & 0.063 & 0.8 \\
\hline $3.21(66 \%)$ & 154.11 & 701.42 & 0.066 & 0.02 \\
\hline $4(85 \%)$ & 140.60 & 625.56 & 0.107 & 0.43 \\
\hline \multirow{3}{*}{$\begin{array}{l}\text { Diameter } \\
\text { (D) }(\mathrm{mm}) / \% \text { stenosis }\end{array}$} & \multicolumn{4}{|c|}{ Location $X=5 \mathrm{D}$} \\
\hline & \multicolumn{2}{|c|}{$\mathrm{WSS}_{\max }(\mathrm{Pa})$} & \multicolumn{2}{|c|}{$\mathrm{WSS}_{\min }(\mathrm{Pa})$} \\
\hline & Normal & Hyperaemic & Normal & Hyperaemic \\
\hline $3(33 \%)$ & 5.21 & 43.43 & 0.063 & 0.95 \\
\hline $3.21(66 \%)$ & 15.93 & 80.70 & 0.155 & 0.24 \\
\hline $4(33 \%)$ & 16.46 & 102.62 & 0.14 & $0 . .31$ \\
\hline
\end{tabular}

wall corresponding to the different phases $(1.62 \mathrm{~s}$, $2.05 \mathrm{~s}, 2.191 \mathrm{~s}$ and $2.26 \mathrm{~s}$ ) of cardiac cycle in normal condition. The diameter of $33 \%$ stenosed artery under study is $3 \mathrm{~mm}$ and its length was extended to $5 \mathrm{D}$ on both ends for obtaining a fully developed flow. The same procedure was followed for the remaining two patient cases with $66 \%$ and $85 \%$ stenosis. The throat of the stenosis is positioned at $3.29 \mathrm{~mm}$ from the starting point $(\mathrm{x}=0)$ of CT scanned image. The WSS starts increasing from pre-stenotic region (from $\mathrm{x}=0$ onwards) in all the four phases and reaches a maximum value at the location of stenosis. At pre-stenotic region, the WSS value is $\sim 12 \mathrm{~Pa}$ for $1.62 \mathrm{~s}$ and is $\sim 1.24 \mathrm{~Pa}$ for $2.05 \mathrm{~s}$ of cardiac cycle. The WSS value reaches a maximum value of $48.08 \mathrm{~Pa}$ in normal condition at the maximum flow rate $(1.62 \mathrm{~s})$ and then drops down, but lies below the lower limit in the allowable range $(2 \mathrm{~Pa})$ in the post stenotic region. The WSS then start increasing as the high level fluctuations because of surface irregularities, turbulence, reattachment and recirculation, which are more severe for higher percentage stenosis, as explained in the subsequent sections.

Figures $8 \mathrm{~b}$ and $8 \mathrm{c}$ show the WSS variation along the flow direction for both $66 \%$ and $85 \%$ stenosis cases in normal condition. The position of stenosis from the starting point of CT scan image is different in this cases i.e., for $66 \%$, the throat position is $3.89 \mathrm{~mm}$ and for $85 \%$, it is $8.68 \mathrm{~mm}$. The minimum and maximum values of WSS at $1.62 \mathrm{~s}$ are close to $12 \mathrm{~Pa}$ and $165 \mathrm{~Pa}$ for $66 \%$ and $14.1 \mathrm{~Pa}$ and $260 \mathrm{~Pa}$ for $85 \%$ respectively. A steep drop in WSS value is observed immediately after the maximum value like the previous case. Secondary peaks are also observed in the post-stenotic region of both $66 \%$ and $85 \%$ stenosis. In all cases, strong oscillations of WSS are observed after the stenotic area at the different time phase of cardiac cycle. It represents the reattachment locations of flow separation zones after the stenosis. After the secondary peak region, the WSS reduces and approaches the upstream WSS values.

Figures 9a, b, c represent the WSS distribution of $33 \%, 66 \%$ and $85 \%$ stenosis cases for hyperaemic condition. The results follow similar trend as in the normal condition. For $33 \%$ stenosis, during hyperaemic condition, the WSS values at $1.62 \mathrm{~s}$ and $2.05 \mathrm{~s}$ of cardiac cycle in pre-stenotic region are $\sim 44.31 \mathrm{~Pa}$ and $\sim 10.28 \mathrm{~Pa}$. The minimum and maximum values of WSS at maximum flow rate are close to $44.31 \mathrm{~Pa}$ and $430 \mathrm{~Pa}$ for $33 \%, 49.4 \mathrm{~Pa}$ and 844 $\mathrm{Pa}$ for $66 \%$ and $28.22 \mathrm{~Pa}$ and $1326 \mathrm{~Pa}$ for $85 \%$ respectively. The study reveals that, the peak WSS value is higher by two times or more compared to the permissible limit in hyperaemic condition. This can create damages to the layers of endothelium cells (Fig. 10b). Stenosis severity is also one of the most important factor that affects flow behaviour. Comparing the WSS plots of each case, it is understood that the size of the stenosis has a significant effect on the WSS. The maximum WSS value at normal flow conditions of $66 \%$ stenosis case $(162 \mathrm{~Pa})$ is much higher than the maximum WSS value of $33 \%$ case $(48.08 \mathrm{~Pa})$. To have better understanding of process, the WSS contours are plotted for normal and hyperaemic condition and are given in Fig. 10a and b. The location of the spatial maximum WSS on the surface of artery shifts in accordance with the change in size and geometry of the stenosis. It also depends on the location of the stenosis and narrowness of the flow area (Fig. 10a and b).The Fig. 10 represents contour plots showing WSS distribution of three stenosis cases under normal and hyperaemic conditions at peak flow (1.62s). The value of WSS is between $0 \mathrm{~Pa}$ to 241.38 $\mathrm{Pa}$ in almost all areas under normal flow conditions, except at the centre of the stenosis. In $33 \%$ and $66 \%$ hyperaemic flow cases, the WSS values observed at 
B. Thomas et al. / JAFM, Vol. 14, No. 5, pp. 1469-1482, 2021.

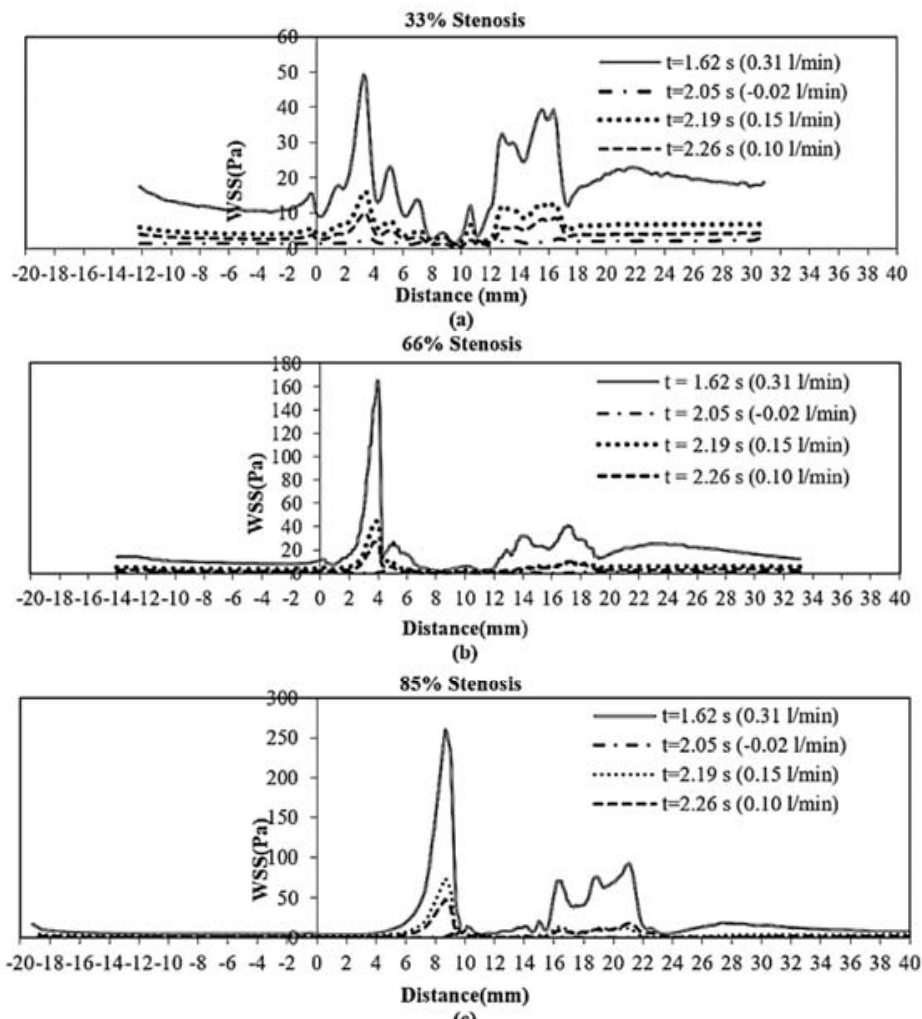

(c)

Fig. 8. WSS variation along the artery wall for different phase of cardiac cycle in normal condition. (a) $33 \%$; (b) $66 \%$; (c) $85 \%$.

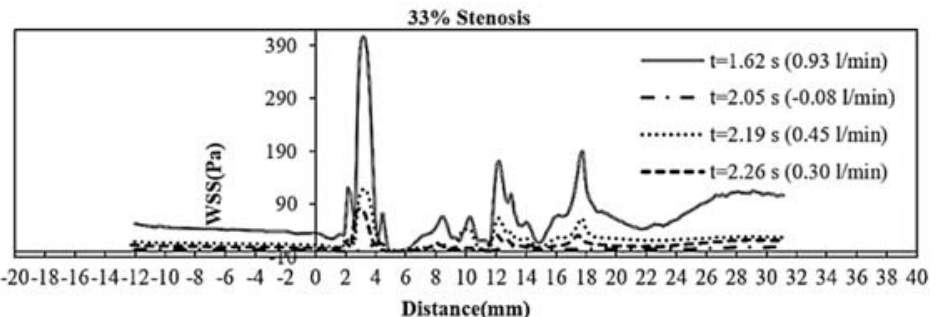

(a)

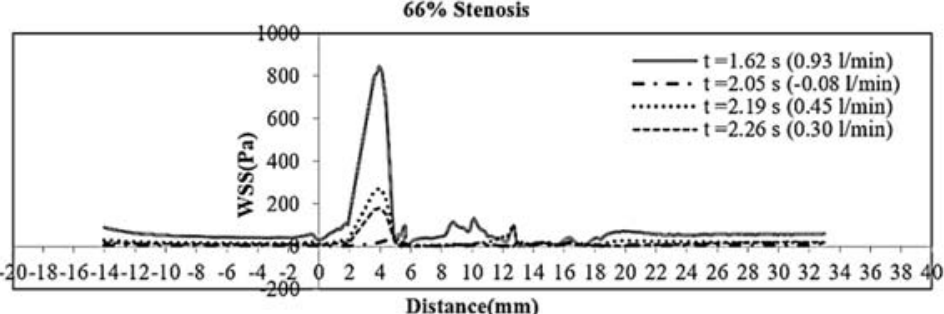

(b)

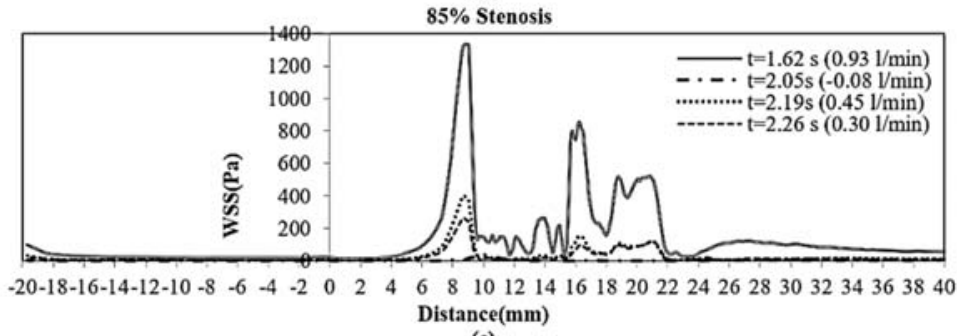

(c)

Fig. 9. WSS variation along the artery wall for different phase of cardiac cycle in hyperaemic condition. (a) $33 \%$; (b) $66 \%$; (c) $85 \%$. 


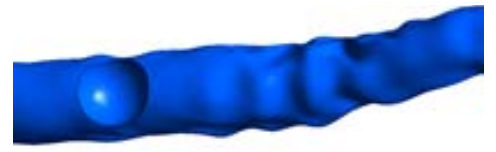

(a)33\% stenosis

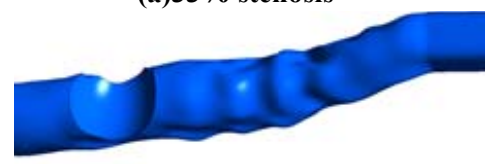

(a) 66\% stenosis

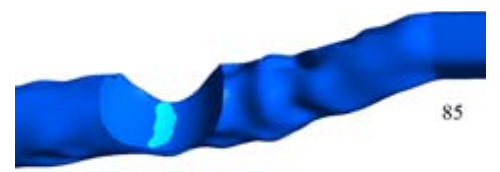

(a) $85 \%$ stenosis

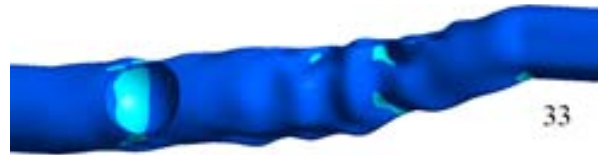

(b) $33 \%$ stenosis

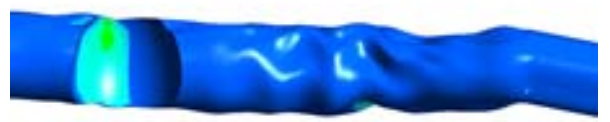

(b) $66 \%$ stenosis

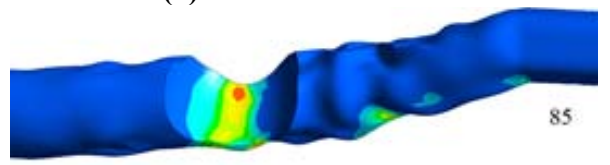

(b) $85 \%$ stenosis

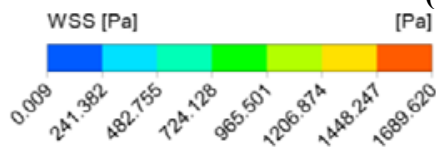

Fig. 10. Contour plots of WSS at normal and hyperaemic condition for different \% stenosis at maximum flow (i.e., 1.62 s of cardiac cycle). (a) Normal condition; (b) Hyperaemic condition.

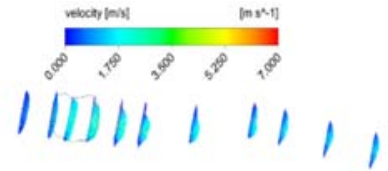

(a)

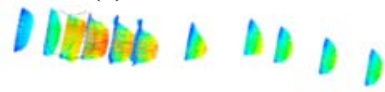

(b)

Fig. 11. Velocity field profile for $66 \%$ stenosis. (a) Normal flow; (b) Hyperaemic flow.

the stenosis region are $430 \mathrm{~Pa}$ and $844 \mathrm{~Pa}$ respectively. A relatively high WSS is observed for $85 \%$ case at the centre of the stenosis. In $85 \%$ case, the value of WSS at the centre of the stenosis is much higher than that of other two cases i.e., $1326 \mathrm{~Pa}$. To understand more about the nature of the flow, velocity profiles are also plotted. The Fig. $11 \mathrm{a}$ and $11 \mathrm{~b}$ depict the velocity field profiles in the luminal channel during systole of $66 \%$ stenosis case under normal and hyperaemic conditions. The flow pattern is clearly visible from the figures. The velocity profile is parabolic in the direction of flow before reaching stenosis and then changes to plug profile when the flow passes through the narrowed area near the stenosis, at jet speed. The flow profile returns back to parabolic profile after passing the stenosis. These plots give a better idea about the stressed and recirculation areas after the stenosis under normal and hyperaemic conditions. It is inferred that the flow becomes turbulent immediately after the constriction zone owing to sudden change in flow pattern around the

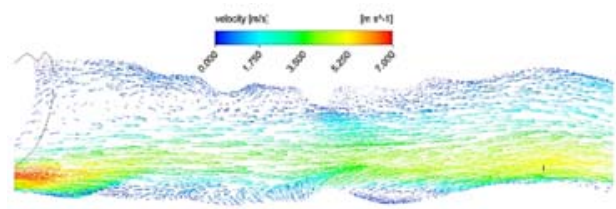

(a)

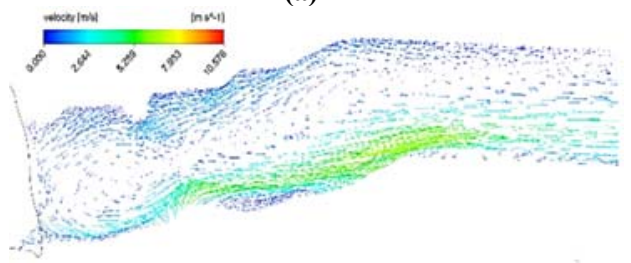

(b)

Fig. 12. Vector field along flow direction under hyperaemic condition. (a) $66 \%$ stenosis; (b) $85 \%$ stenosis.

plaque and increased fluid velocity near the region of stenosis. The velocity fluctuations inside the vessel constriction area get aggravated with increase in the fat plaque deposits inside the artery.

Further the velocity vector diagrams are plotted for $66 \%$ stenosis case (Fig. 12a) under hyperaemic flow condition. Due to a sudden increase in the velocity (Fig. 11b) immediately after stenosis, the $\mathrm{Re}$ increases considerably leading to the development of turbulent structures. To have better insight to the process, Reynolds number is also calculated. The maximum Reynolds number at upstream side of stenosis is $\sim 1680$. After stenosis it reaches a maximum value of $\sim 5005$ whereas maximum value of $\mathrm{Re}$ reaches up to 6256 for $85 \%$ stenosis case (Fig.12b). The range of Re values justify the use of turbulence model in the study. Drastic change in velocity consequent to the change in Re can be observed after stenosis at hyperaemic condition 
(Fig.12a). The turbulence formation depends on the amount of flow and size of stenosis. It also influences the reattachment locations of separation zones after the stenosis. The position and size of the recirculation regions depend on the shape and size of the stenosis. Fry (1969) observed that the high WSS and recirculation regions activate platelets and therefore contribute to thrombus formation. From the Fig. $12 \mathrm{a}$ and $12 \mathrm{~b}$ it is concluded that, the effect of recirculation on the walls gives raise to future lesions areas and lead to high level secondary WSS fluctuations for higher percentage of stenosis (Fig. $9 b$ and $c)$.

\subsection{Pressure distribution for Patient specific model with different stenosis level}

This section discusses the pressure variation occurring inside a stenosed artery with rigid walls. The pressure difference before and after the stenosis is plotted against the flow rate for three different diseased coronary arteries with stenosis severities of $33 \%, 66 \%$ and $85 \%$ (Fig. 13 ).

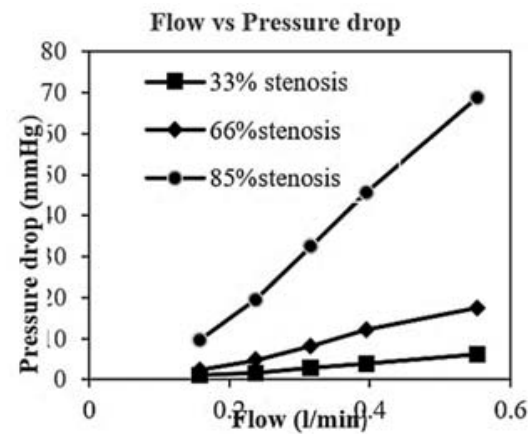

Fig. 13. Pressure drop for different degrees of stenosis.

The mean flow rate varies from about $0.158 \mathrm{l} / \mathrm{min}$ to $0.553 \mathrm{l} / \mathrm{min}$ for all cases. With higher degrees of stenosis, considerable pressure drop is observed over the constriction zone (Fig. 13). A remarkable increase in pressure drop is seen for the three cases of stenosis with increase in flow rates. Also, at the same flow rate, the increase in the stenosis percentage can result in higher pressure drop. The pressure drop is significantly increased with the degree of stenosis as clearly seen in the case of $85 \%$ stenosis.

\subsection{Fractional flow reserve (FFR)}

To study the impact of stenosis growth and its criticality on blood flow, the FFR is plotted against percentage stenosis for each flowrate (Table 5 and Fig. 14). Thus, the relationship between FFR and percentage stenosis are established by means of second order polynomials in the form of $\mathrm{ax}^{2}+\mathrm{bx}+\mathrm{C}$ for each flowrate. Five Equations indicated in the Fig. 14 corresponds to different flow rates. It may be noted that these equations fit very well the data points with regression coefficients nearing to one. Each polynomial has different coefficients $(a, b, c)$ for the variables $\left(\mathrm{x}^{2}, \mathrm{x}\right)$ correspond to each flow rate (Table 6). These five equations can be used to calculate the FFR for an unknown percentage stenosis corresponding to that flowrate (Table 7). Now, thus calculated five values can be used for plotting the FFR vs stenosis. Figure 15 shows the curve corresponding to the $45 \%$ stenosis obtained from these calculations. Hence, if one would like to determine the criticality of stenosis level, these equations can be utilised and FFR can be calculated (Table 7 and Fig. 15) for different flow rates.

Table 5 FFR vs percentage stenosis for the variation in mean discharge.

\begin{tabular}{|c|c|c|c|c|c|}
\hline Q1/min & 0.158 & 0.237 & 0.316 & 0.395 & 0.553 \\
\hline \%stenosis & \multicolumn{5}{|c|}{ FFR } \\
\hline 0.33 & 0.987 & 0.967 & 0.946 & 0.931 & 0.896 \\
\hline 0.66 & 0.932 & 0.867 & 0.788 & 0.722 & 0.617 \\
\hline 0.85 & 0.828 & 0.700 & 0.602 & 0.510 & 0.358 \\
\hline
\end{tabular}

Table 6 Coefficients of FFR and percentage stenosis relation for each mean flow rate.

\begin{tabular}{|c|c|c|c|c|}
\hline \multirow{2}{*}{$\begin{array}{c}\mathrm{Q} \\
(1 / \mathrm{min})\end{array}$} & \multicolumn{3}{|c|}{ Coefficients $\left(\mathrm{x}^{2}+\mathrm{x}+\mathrm{c}\right)$} & $\begin{array}{c}\text { FFR correspond } \\
\text { to unknown } \\
\text { percentage } \\
\text { stenosis }\end{array}$ \\
\cline { 2 - 5 } & $\mathrm{x}^{2}$ & $\mathrm{x}$ & $\mathrm{c}$ & ${ }^{*} 0.45$ \\
\hline 0.158 & -0.7319 & 0.559 & 0.8819 & 0.985 \\
\hline 0.237 & -1.1019 & 0.7859 & 0.828 & 0.959 \\
\hline 0.316 & -0.961 & 0.4731 & 0.8946 & 0.913 \\
\hline 0.395 & -0.9307 & 0.2886 & 0.9371 & 0.879 \\
\hline 0.553 & -0.987 & 0.1324 & 0.9604 & 0.820 \\
\hline * Indicates unknown percentage stenosis \\
\hline
\end{tabular}

FFR across the stenosis significantly decreases with the increase in the degree of stenosis and the flow rate (Fig. 15).

The results show that the FFR value ranges from 0.98 to 0.89 for $33 \%$ stenosis at varying flow rates from normal to hyperaemic condition $(0.158-0.553$ $1 / \mathrm{min})$. For the higher flow rates, the FFR value even reaches near to the critical value of 0.8 even if stenosis size is $33 \%$. In the case of $66 \%$ stenosis, the FFR value ranges from 0.93 to 0.61 . The FFR value crosses the critical value of 0.80 when flow rate is above $0.3 \mathrm{l} / \mathrm{min}$. Further, the FFR value ranges from 0.82 to 0.35 in case of $85 \%$ stenosis. From Fig. 13 and 15 , it was concluded that $85 \%$ case stenosis is very critical even for small flow rate (i.e., normal condition) whereas even a low level stenosis also becomes critical at hyperaemic flows (Fig. 15). Based on this study, it is found that up to $45 \%$ stenosis, the FFR value is within the acceptable limit of 0.8 (when flow rate changes from normal to hyperaemic condition). It may be noted the curve corresponding $45 \%$ stenosis is not a measured stenosis level but a derived information as explained earlier. 


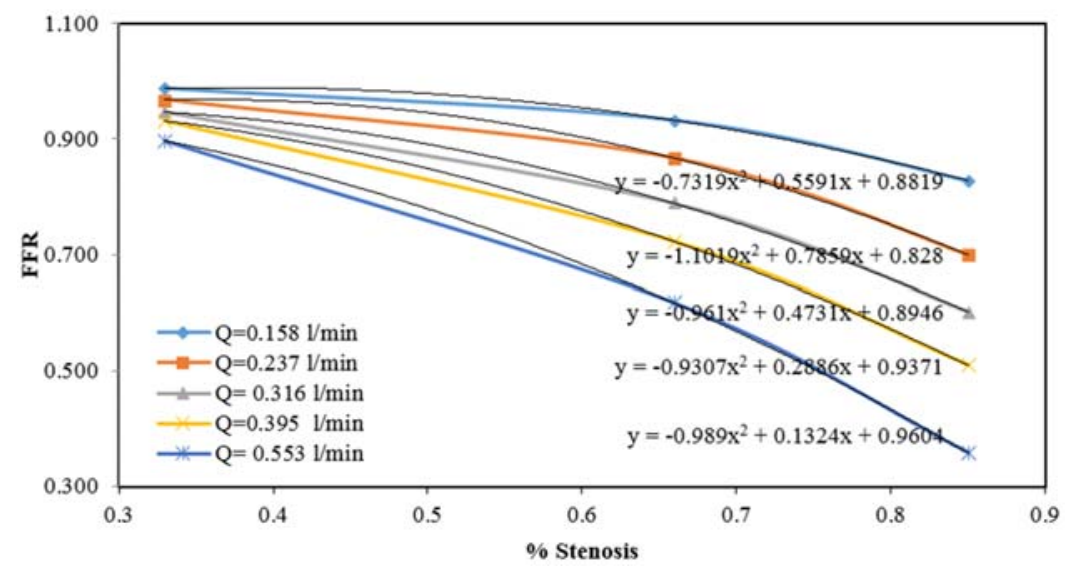

Fig. 14. FFR vs percentage Stenosis (from normal to hyperaemic flow condition).

Table 7 FFR vs flow rate for different percentage stenosis.

\begin{tabular}{|c|c|c|c|c|}
\hline \%stenosis & 0.33 & 0.66 & 0.85 & ${ }^{*} 0.45$ \\
\hline Q (1/min) & FFR & FFR & FFR & FFR \\
\hline 0.158 & 0.987 & 0.932 & 0.828 & 0.985 \\
\hline 0.237 & 0.967 & 0.867 & 0.700 & 0.959 \\
\hline 0.316 & 0.946 & 0.788 & 0.602 & 0.913 \\
\hline 0.395 & 0.931 & 0.722 & 0.510 & 0.879 \\
\hline 0.553 & 0.896 & 0.617 & 0.358 & 0.820 \\
\hline * Indicates unknown percentage stenosis \\
\hline
\end{tabular}

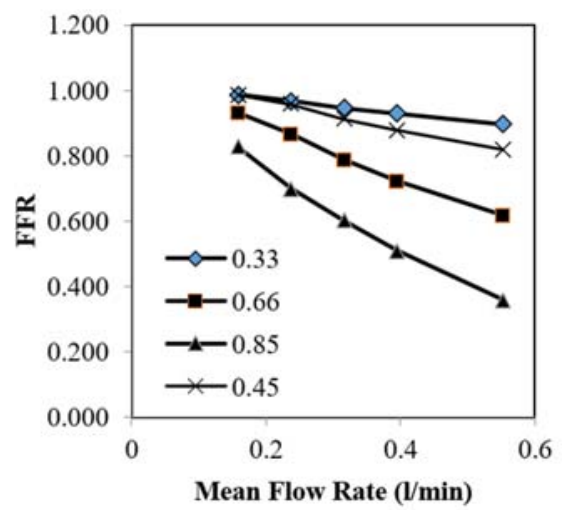

Fig. 15. FFR vs Mean flow rate relation for different percentage stenosis (FFR is simulated for $45 \%$ stenosis, based on Table $6 \& 7$ ).

The importance of this relation is that the details of pressure drop and corresponding FFR can be obtained through non-invasive methods. Thus, the information increases the accuracy of diagnosis and assists the treatment planning subsequent to the diagnosis. The result is more sensitive and specific to each patient case, rather than generalising severity by thump rules and coefficients. The Flow rate to FFR relation of each case gives clear projections about the possible criticalities at the less active and highly active heart rates. It also helps in the prediction of the plaque accretion and propagation dynamics.

\section{Conclusion}

CAD remains as a major cause of death all around the world till today. Early diagnosis and medication is most important in the treatment of CAD. The flow through blood vessel greatly influences the plaque morphology and composition and hence plays a significant role in propagation, rupture and thrombosis of the plaques. The ongoing practices of clinical diagnosis lack sensitivity and specificity towards early detection of vulnerable plaques. The current study demonstrates that the CFD modelling of flow through stenosed artery can produce reasonably accurate results of WSS and thereby can play a significant role in the diagnosis. This result become very much significant because of the difficulties encountered while getting hemodynamic parameters directly from measurements by using pressure transducer catheter in real situation.

The study analysed the flow - pressure relation and WSS variations in coronary artery with patientspecific asymmetric stenosis cases (realistic geometry) under different flow condition. The study revealed the occurrence of high WSS (peak) in the stenotic region and subsequent drastic reduction in its value towards the downstream. This low WSS area indicates the recirculation and turbulent nature of flow regime. The recirculation region can aggravate the plaque deposition and extension of stenosis leading to the formation of secondary stenosis in the downstream. The velocity forms a plug profile in this region and returns to fully developed flow after stenosis area. Further, the study unravels that the pressure drop across stenosis increases with the increase in the flow rate and the size of stenosis. The demonstrated methodology could be utilised for identifying the chance of aggravation of plaque deposition and the occurrence of secondary stenosis. Further, the study reveals that the FFR reaches the critical value of 0.8 (De Bruyne et al. 2012; Muller et 
al. 2011; Nørgaard et al. 2014) for $66 \%$ and $85 \%$ stenosis cases even at normal flow or at a slightly higher flow rate.

In the present study, a methodology is devised to calculate the FFR value for unknown percentage stenosis based on the simulated results obtained from $33 \%, 66 \%$ and $85 \%$ stenosis. Hence the variation of FFR for unknown percentage stenosis under different flow rate can be evaluated. Such evaluations with different percentage of stenosis reveals that the maximum value of allowable percentage of stenosis is $45 \%$ to keep FFR within safe limit. Therefore, this limit can be used for primary evaluation of stenosis and associated risks. These primary results can be reinforced by analysing more number of patient specific stenosis cases. This investigation is directly related to the survival in patients with cardiovascular disease and is a simple and useful tool for identifying risk in patients undergoing secondary prevention and cardiac rehabilitation programs.

\section{LiMitATIONS}

The present study considered that arterial wall as rigid and neglected the movement of the cardiac muscle. Better predictions can be obtained by incorporating these two characteristics while modelling. Only specific patient cases are considered for the study. It is proposed to apply this concept to more cases. Clinical trials are also suggested in parallel with present practices for proper validation of the methodology.

\section{REFERENCES}

Ahmed, S. A. and D. P. Giddens (1984). Pulsatile poststenotic flow studies with laser Doppler anemometry. Journal of Biomechanics 17(9), 695-705.

Ahmed, S. A. and D. P. Giddens (1983). Velocity measurements in steady flow through axisymmetric stenoses at moderate Reynolds numbers. Journal of Biomechanics 16(7), 505516.

Anderson, J. (1995). Computational Fluid Dynamics. New York McGraw-Hill Education.

Ansys fluent 18.2. Fluent User's Guide (2017) ANSYS Inc.

Antiga, L., M. Piccinelli, L. Botti, B. Ene-Iordache, A. Remuzzi and D. Steinman (2008). An imagebased modeling framework for patient-specific computational hemodynamics. Medical \& Biological Engineering \&Computing 46 (11), 1097-1112.

Attinger, E. O., A. Anne and D. A. McDonald (1966). Use of fourier series for the analysis of biological systems. Biophysical Journal 6(3), 291-304.

Banks, J. and N. W. Bressloff (2007). Turbulence modelling in three- dimensional stenosed arterial bifurcations. ASME Journal Biomechanical Engineering 129(1), 40-50.
Bluestein, D., C. Gutierrez, M. Londono and R. T. Schoephoerster (1999). Vortex shedding in steady flow through a model of an arterial stenosis and its relevance to mural platelet deposition. Annals of Biomedical Engineering 27(6), 763-773.

Celik, I. B., U. Ghia, P. J. Roache and C. J Freitas (2008). Procedure for estimation and reporting of uncertainty due to discretization in CFD applications. Journal of fluids EngineeringTransactions of the ASME, 130(7).

Cheng, C., F. Helderman, D. Tempel, D. Segers, B. Hierck, R. Poelmann, A. van Tol, D. J. Duncker, D. Robbers-Visser, N. T. Ursemand and R. van Haperen (2007). Large variations in absolute wall shear stress levels within one species and between species. Atherosclerosis195(2), 225235.

Davies, P. F., A. Remuzzi, E. J. Gordon, C. F. Dewey and M. A. Gimbrone_(1986). Turbulent fluid shear stress induces vascular endothelial cell turnover in vitro. Proceedings of the national academy of sciences of the United States of America 83(7),2114-2117.

De Bruyne, B., N. H. Pijls, B. Kalesan, E. Barbato, P. A. Tonino, Z. Piroth, N. Jagic, S. MöbiusWinkler, G. Rioufol, N. Witt and P. Kala (2012). Fractional flow reserve-guided PCI versus medical therapy in stable coronary disease. New England Journal of Medicine 367(11), 991-1001.

Deshpande, M. and D. Giddens (1980). Turbulence measurements in a constricted tube. Journal of Fluid Mechanics 97, 65-89.

Fournier, R. L. (2007). Basic Transport Phenomena in Biomedical Engineering. Taylor \& Francis, London, UK, 2007.

Fry, D. L. (1969). Certain histological and chemical response of the vascular interface to acutely induced mechanical stress in the aorta of the dog. Circulation Research 39, 58-65.

Fung, Y. C. (1997). Biomechanics: Circulation. Springer New York (2nd edn.).

Garcia, D., L. Kadem, D. Savéry, P. Pibarot and L. G. Durand (2006). Analytical modeling of the instantaneous maximal transvalvular pressure gradient in aortic stenosis. Journal of Biomechanics 39(16), 3036-3044.

Ghalichi, F., X. Deng, A. D. Champlain, Y. Douville, M.King and R. Guidoin (1998). Low Reynolds Number Turbulence Modeling of Blood Flow in Arterial Stenoses. Biorheology 35(4-5), 281294.

Golpayeghani, A.T., S. Najarian and M. Movahedi (2008). Numerical simulation of pulsatile flow with Newtonian and nonNewtonianbehavior in arterial stenosis. Iran Cardiovascular Research Journal 1,167-174.

Hinze, J. O. (1975). Turbulence. McGraw-Hill, New York. 
Jabir, E., and S. Anil Lal (2016). Numerical analysis of blood flow through an elliptic stenosis using large eddy simulation. Proceedings of the Institution of Mechanical Engineers, Part H: Journal of Engineering in Medicine 230, 70926.

Jahangiri, M., M. Saghafian and M. R. Sadeghi (2017). Numerical Simulation of NonNewtonian Models Effect on Hemodynamic Factors of Pulsatile Blood Flow in Elastic Stenosed Artery. Journal of Mechanical Science and Technology 31 (2), 1003-1013.

Johnston, B. M., P. R. Johnston, S. Corney and D. Kilpatrick (2006). Non-Newtonian blood flow in human right coronary arteries: Transient simulations. Journal of Biomechnics $39,1116-1128$.

Johnston, B. M., P. R. Johnston, S. Corney and D. Kilpatrick (2004). Non- Newtonian blood flow in human right coronary arteries: steady state simulations. Journal of Biomechnics 37(5), 709-720.

Kumar, A., O. Y. Hung, M. Piccinelli, P. Eshtehardi, M. T. Corban, D. Sternheim and H. Samady (2018). Low coronary wall shear stress is associated with severe endothelial dysfunction in patients with nonobstructive coronary artery disease. JACC: Cardiovascular Interventions 11, 2072- 2080.

Mahalingam, A., U. U. Gawandalkar, G. Kini, A. Buradi, T. Araki, N. Ikeda, A. Nicolaides, J. R. Laird, L. Saba and J. S. Suri (2016). Numerical analysis of the effect of turbulence transition on the hemodynamic parameters in human coronary arteries. Cardiovascular Diagnosis and Therapy 6(3), 208-220.

Muller, O., F. Mangiacapra, A. Ntalianis, K. M. Verhamme, C. Trana, M. Hamilos, J. Bartunek, M. Vanderheyden, E. Wyffels, G. R. Heyndrickx and F. J. van Rooij (2011). Longterm follow-up after fractional flow reserveguided treatment strategy in patients with an isolated proximal left anterior descending coronary artery stenosis. JACC. Cardiovascular Interventions 4(11), 1175-82.

Nørgaard, B. L., J. Leipsic, S. Gaur, S. Seneviratne, B. S. Ko, H. Ito, J. M. Jensen, L. Mauri, B. De Bruyne, H. Bezerra, K.Osawa, M.Marwan, C. Naber, A. Erglis, Seung-Jung Park, E. H. Christiansen, A. Kaltoft, J. F. Lassen , H. E. Bøtker, S. Achenbach and NXT Trial Study Group (2014). Diagnostic performance of noninvasive fractional flow reserve derived from coronary computed tomography angiography in suspected coronary artery disease the NXT trial (analysis of coronary blood flow using CT angiography: next steps). Journal of the American College of Cardiology 63(12), 114555.

Ojha, M., R. S. Cobbold, K. W. Johnston and R. L. Hummel (1989). Pulsatile flow through constricted tubes: an experimental investigation using photochromic tracer methods. Journal of Fluid Mechanics 203(1), 173-197.

Pedley, T. J. (1980). The fluid mechanics of large blood vessels. Cambridge University Press. Cambridge.

Pijls, N. H. and J. W. Sels (2012). Functional measurement of coronary stenosis. Journal of the American College of Cardiology 59, 104557.

Ryval, J., A. G. Straatman and D. A. Steinman (2004). Two-Equation turbulence modeling of pulsatile flow in a stenosed Tube. ASME Journal Biomechanical Engineering 126(5), 625-635.

Samady H., P. Eshtehardi, M. C. McDaniel, J. Suo, S. S. Dhawan, C. Maynard, L. H. Timmins, A. A. Quyyumi and D. P. Giddens (2011). Coronary artery wall shear stress is associated with progression and transformation of atherosclerotic plaque and arterial remodeling in patients with coronary artery disease.Circulation 124,779-788.

Stein, P. D. and H. N. Sabbah (1976). Turbulent Blood Flow in the Ascending Aorta of Humans with Normal and Diseased Aortic Valves. Circulation Research 39, 58-65.

Stone, G. W., A. Maehara, A. J. Lansky, B. deBruyne, E. Cristea, G. S. Mintz, R. Mehran, J. McPherson, N. Farhat, S. P. Marso, H. Parise, B. Templin, R. White, Z. Zhang and P.W. Serruys (2011). PROSPECT Investigators A prospective natural-history study of coronary atherosclerosis. The New England Journal of Medicine 364, 226-235.

Tan, F. P., G. Soloperto, S. Bashford S, N. B. Wood, S. Thom, A. Hughes and X. Y. Xu (2008). Analysis of flow disturbance in a stenosed carotid artery bifurcation using twoequation transitional and turbulence models. Journal of Biomechanical Engineering 130(6).

Thomas, B. and K. S. Sumam (2016). Blood flow in human arterial system- A review. Procedia Technology 24, 339-346.

Varghese, S. S. and S. H. Frankel (2003). Numerical modeling of pulsatile turbulent Flow in stenotic vessels. ASME Journal Biomechanical Engineering 125(4), 445-460.

Varghese, S. S., S. H. Frankel and P. F. Fischer (2007). Direct numerical simulation of stenotic flows. Part 2. Pulsatile flow. Journal of Fluid Mechanics 582(1), 281-318.

Winter, D. C. and R. M. Nerem (1984). Turbulence in pulsatile flows. Annals of Biomedical Engineering 12(4), 357-69.

Wiwatanapataphee, B., Y. H. Wu, T. Siriapisith and B. Nuntadilok (2012). Effect of branchings on blood flow in the system of human coronary arteries. Mathematical Biosciences and Engineering 9, 199-21 